\title{
Breast Milk Iodine and Iodine Status of Breast-Fed Infants
}

\author{
Golam Morshed Molla1, M Iqbal Arslan², Mafruha Tazkin Milky³
}

\begin{abstract}
Background: Breast milk is the only source of iodine for exclusively breast-fed infants. Iodine status of breast-fed infants depends on iodine in breast milk and also number of feeding in 24 hours. Iodine deficiency and iodine excess both have bad impact on infant's health. Objective: To measure the iodine in breast milk and to evaluate iodine status of their breast-fed infants. Materials and method: This observational analytical study was carried out in the department of Biochemistry, Bangabandhu Sheikh Mujib Medical University, Dhaka with active cooperation of Kumudini Women's Medical College Hospital, Mirzapur, Tangail involving fifty lactating mothers and their exclusively breast-fed infants. Early morning urine and breast milk samples were collected in dry and clean plastic container free from any chemical contamination. Urinary iodine was used as indicator for assessing iodine status. All statistical analyses were done by using SPSS (statistical programme for social science) 12 version software package for Windows. Results: The median (range) urinary iodine concentration of lactating mothers and their breast-fed infants were $225.25 \mu \mathrm{g} / \mathrm{L}$ (61.50-530.00) and $225.75 \mu \mathrm{g} / \mathrm{L}$ (100.50-526.00) respectively. The median (range) breast-milk iodine concentration was $157 \mu \mathrm{g} / \mathrm{L}$ (54.50-431.50) which was more than three times of recommended minimum concentration $(50 \mu \mathrm{g} / \mathrm{L})$. Only 2 (4\%) lactating mothers had mild biochemical iodine deficiency (UIE, 50-99 $\mu \mathrm{g} / \mathrm{L}$ ). There was no biochemical iodine deficiency of breast-fed infants. Iodine in breast milk of lactating mothers was positively correlated with their urinary iodine excretion $(p<0.01)$. Infant's urinary iodine was positively correlated with iodine concentration in breast milk $(p<0.01)$ and with urinary iodine of lactating mothers $(p<0.01)$. Conclusion: Lactating mothers and their breast-fed infants in this study were iodine sufficient. If iodine content of breast-milk is within normal range, 10-12 numbers of feeding in 24 hours for infants is enough to get sufficient iodine from their mother's milk.
\end{abstract}

Keywords: Urinary iodine excretion (UIE); breast milk iodine concentration; iodine status of lactating mothers; breast-fed infants.

Delta Med Col J. Jul 2015;3(2):74 - 77

\section{Introduction}

Human infants are sensitive to maternal iodine nutrition during fetal development and later during breast feeding. ${ }^{1}$ Iodine deficiency during post-partum period has the potential to affect neonatal neuropsychointellectual development. ${ }^{2}$ Breast milk is the only source of iodine for the

1. Associate professor, Department of Biochemistry, Ashiyan Medical College, Dhaka, Bangladesh.

2. Professor, Department of Biochemistry, BSMMU, Dhaka, Bangladesh.

3. Consultant, Department of Gynae \& Obs., Verk Mother \& Children Hospital, Savar, Dhaka, Bangladesh.

Correspondence: Dr. Golam Morshed Molla. e-mail: golammorshed56@yahoo.com 
exclusively breast-fed neonates and infants. Bangladesh is an iodine deficient region ${ }^{3}$ and the government of Bangladesh, with assistance of UNICEF had initiated a universal salt iodinization programme to provide iodized salt by the middle of 1994. Excessive iodine intake also causes hyperthyroidism, iodine induced hypothyroidism, autoimmune thyroid diseases. ${ }^{4-6}$ Despite the importance of iodine for infants' health, there have been limited studies addressing iodine status of lactating mothers and their breast-fed infants, breast milk iodine concentration and whether exclusively breast-fed infants get sufficient iodine from their mother's milk. For these reasons, this study was designed and urinary iodine excretion (UIE) was used as the indicator for assessing iodine status.

\section{Materials and method}

This observational analytical study was carried out in the department of Biochemistry, Bangabandhu Sheikh Mujib Medical University (BSMMU), Dhaka with active cooperation of Kumudini Women's Medical College Hospital, Mirzapur, Tangail. Fifty lactating mothers and their exclusively breast-fed infants were included in this study. The age of the lactating mothers and their breast-fed infants were 20-40 years and 3-180 days respectively and they had no known endocrine, renal, cardiovascular and liver diseases. All the subjects were informed in details about the nature and purpose of the study and were included in the study only when they had given their written consent. Early morning urine and breast milk samples were collected in dry and clean plastic container free from any chemical contamination. Temporarily these were kept in an ice box for preservation just after collection and during transportation and finally these were preserved in a $-35^{\circ} \mathrm{C}$ freezer till the test was performed. Urinary iodine of lactating mothers and their breast-fed infants and breast-milk iodine were estimated by spectrophotometer based on the principle of Sandell-Clothoff reaction. ${ }^{7-9}$ All statistical analyses ware done by using SPSS (Statistical Programme for Social Science) version 12 software package for Windows. Urinary iodine and breast milk iodine level do not follow the normal distribution. So Spearman's correlation coefficient test (' $r$ ' test) was done to see the correlation. The significance test was done at $95 \%$ confidence level.

\section{Results}

The mean \pm SD (range) of age of lactating mothers was $24.92 \pm 4.35$ (20-36) years and of their breast-fed infants were $78.22 \pm 59.05$ (5-180) days.

The median (range) urinary iodine concentration of lactating mothers and their breast-fed infants were $225.25 \mu \mathrm{g} / \mathrm{L}(61.50-530.00)$ and $225.75 \mu \mathrm{g} / \mathrm{L}$ (100.50-526.500) respectively. The median (range) breast-milk iodine concentration was $157 \mu \mathrm{g} / \mathrm{L}$ (54.50-431.50) (Table-I).

Table I: Distribution of breast milk iodine, urinary iodine of lactating mothers and urinary iodine of their breast-fed infants

\begin{tabular}{lcc}
\hline Parameter & Median & Range \\
\hline Breast milk iodine $(\boldsymbol{\mu g} / \mathrm{L}) \mathrm{n}=\mathbf{5 0}$ & 157 & $54.00-431.50$ \\
Mothers urinary iodine $(\boldsymbol{\mu g} / \mathrm{L}) \mathrm{n}=\mathbf{5 0}$ & 225.25 & $61.50-530.00$ \\
Infants urinary iodine $(\boldsymbol{\mu g} / \mathrm{L}) \mathrm{n}=\mathbf{5 0}$ & 225.75 & $100.50-530.50$ \\
\hline
\end{tabular}

Out of 50 lactating mothers, only 2 (4\%) had mild biochemical iodine deficiency (UIE, 50-99 $\mu \mathrm{g} / \mathrm{L}$ ) (Table-II). There was no biochemical iodine deficiency of breast-fed infants (UIE $\geq 100 \mu \mathrm{g} / \mathrm{L}$ ) (table-III).

Table II: Iodine status of lactating mothers (N=50)

\begin{tabular}{lcc}
\hline Parameter & Frequency & Percentage \\
\hline $\begin{array}{l}\text { Moderate to severe deficiency } \\
\text { (Median urinary iodine: }<\mathbf{5 0} \boldsymbol{\mu g} / \mathrm{L})\end{array}$ & 0 & 0 \\
$\begin{array}{l}\text { Mild deficiency } \\
(\text { Median urinary iodine: } \mathbf{5 0}-\mathbf{9 9} \boldsymbol{\mu g} / \mathrm{L})\end{array}$ & 2 & 5 \\
$\begin{array}{l}\text { Normal } \\
(\text { Median urinary iodine: } \mathbf{2} \mathbf{1 0 0} \boldsymbol{\mu g} / \mathrm{L})\end{array}$ & 48 & 96 \\
\hline
\end{tabular}


Table III: Iodine status of breast-fed infants $(\mathrm{N}=\mathbf{5 0})$

\begin{tabular}{lcc}
\hline Parameter & Frequency & Percentage \\
\hline $\begin{array}{l}\text { Deficiency } \\
\text { (Median urinary iodine: }<100 \mu \mathrm{g} / \mathrm{L})\end{array}$ & 0 & 0 \\
$\begin{array}{l}\text { Normal } \\
(\text { Median urinary iodine: } \geq 100 \mu \mathrm{g} / \mathrm{L})\end{array}$ & 50 & 100 \\
\hline
\end{tabular}

Iodine in breast-milk of lactating mothers was positively correlated with their urinary iodine excretion $(\mathrm{P}<0.01)$ (Fig 1). Infants' urinary iodine was positively correlated with iodine concentration in breast milk $(\mathrm{p}<0.01)$ and also positively correlated with urinary iodine of lactating mothers $(\mathrm{p}<0.01)$ (Fig $1 \& 2)$. Out of 50 breast-fed infants, 37 (74\%) infants were fed 10-12 times, $11(22 \%)$ infants were fed more than 12 times and $2(4 \%)$ were fed less than 10 times in 24 hours.
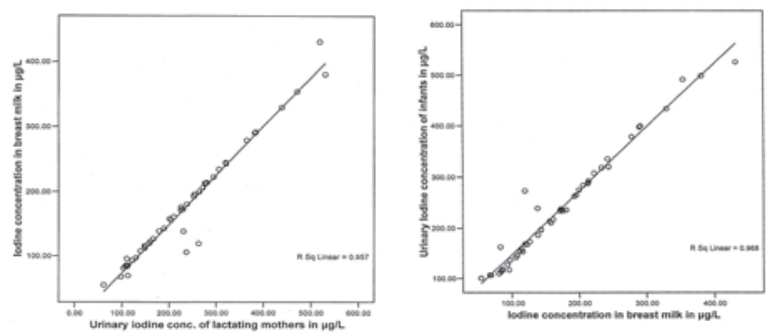

Fig 1 : Correlation between Fig 2 : Correlation between urinary iodine and breast infants' urinary iodine and milk iodine of lactating breast milk iodine mothers

\section{Discussion}

This study was aimed to assess the iodine status of lactating mothers and their exclusively breast-fed infants, to evaluate whether maternal iodine status reflects the iodine status of their exclusively breast-fed infants and how to predict the iodine content of breast milk. Urinary iodine, breast milk iodine of fifty lactating mothers and urinary iodine of their breast-fed infants were measured. Median urinary iodine concentration of lactating mothers was $225.25 \mu \mathrm{g} / \mathrm{L}$ which was within normal range. Out of fifty lactating mothers, 48 (96\%) mothers had no biochemical iodine deficiency. Only 2 (4\%) mothers had mild biochemical iodine deficiency. According to the WHO, lactating mothers of this study were iodine sufficient. ${ }^{6}$ The median urinary iodine concentration of breast-fed infants was
$225.75 \mu \mathrm{g} / \mathrm{L}$ which was normal. It indicates there was no biochemical iodine deficiency of breast-fed infants and they get sufficient iodine from their mother's milk. The median breast milk concentration was $157 \mu \mathrm{g} / \mathrm{L}$ which was within optimum range ${ }^{8}$, but more than three times of recommended minimum concentration. ${ }^{10}$ It was observed that two mothers had mild biochemical iodine deficiency but iodine concentration in breast milk of all lactating mothers was above the recommended minimum concentration. It may be due to mammary glands have ability to uptake iodine against electrochemical gradient. ${ }^{11}$ In this study, breast milk iodine concentration was positively correlated with UIE of lactating mothers $(p<0.01)$. It indicates UIE of lactating mothers predict the iodine content of their breast milk. This finding was consistent with the observation reported by Nelson et al. ${ }^{12}$ and Pong paew et al. ${ }^{8}$ It was also observed that, the lowest value of measured urinary iodine concentration of lactating mothers was $61.50 \mu \mathrm{g} / \mathrm{L}$ and their corresponding breast milk iodine concentration was $54.50 \mu \mathrm{g} / \mathrm{L}$ which was below the optimum concentration but just above the recommended minimum concentration. It indicates that breast milk of lactating mothers with moderate to severe iodine deficiency contain low iodine concentration. This observation was supported by the observation of Pong paew et al. ${ }^{8}$ In this study, infant's urinary iodine concentration was positively correlated with iodine concentration in breast milk $(\mathrm{p}<0.01)$ and also positively correlated with maternal urinary iodine concentration. It indicates that maternal iodine status reflects the iodine status of their breast-fed infants. Out of fifty breast-fed infants, 37 (74\%) infants were breast-fed 10-12 times, $11(22 \%)$ infants were fed more than 12 times, and only $2(4 \%)$ infants were fed less than 10 times in 24 hours. So, apparently it can be said that if breast milk iodine concentration is within normal range; 10-12 numbers of feeding in 24 hours is enough for infants to get sufficient iodine from their mother's milk. 


\section{Conclusion}

Lactating mothers and their breast-fed infants of this study were iodine sufficient. Iodine status of exclusively breast-fed infants can be predicted by the iodine status of their mothers. If iodine content of breast-milk is within normal range, 10-12 numbers of feeding in 24 hours for infants is enough to get sufficient iodine from their mother's milk.

\section{References}

1. Dorea JG. Iodine Nutrition and Breast Feeding. J Trace Elem Med Biol. 2002;16(4):207-20.

2. Chan SS, Hams G, Wiley V, Wilcken B, McElduff A. Postpartum Maternal Iodine Status and the Relationship to Neonatal Thyroid Function. Thyroid. 2003;13(9):873-76.

3. Yousuf HK, Quaz IS, Khan MR, Mohiduzzaman M, Nahar B, Rahman MM, et al. Iodine Deficiency Disorders in Bangladesh. Indian $\mathrm{J}$ Pediatr. 1997;63(1):105-10.

4. Nishiyama S, Mikeda T, Okada T, Nakamura K, Kotani T, HishinumaA. Transient Hypothyroidism or Persistent Hyper Thyrotropinemia in Neonates Born to Mothers with Excessive Iodine Intake. Thyroid. 2004;14(12):1077-83.

5. Luberg P, Perderson B, Knudsen N, Ovesen L, Anderson S. Environmental Iodine Intake Affects the Type of Non Malignant Thyroid Diseases. Thyroid. 2001;11(5):457.

6. WHO. Assessment of Iodine Deficiency Disorders and Monitoring Their Elimination. A Guide for Programme Managers. 2nd ed., Geneva: WHO; 2001.

7. Dunn JT, Crutchfield HE, Gutekunst R, Dun D. Method for Measuring Iodine in Urine. Netherlands: ICCIDD; 1993.

8. Pong paew P, Supawan V, Tungtrongchir R, Phonrat B, Vudhivai N, Chantaranipapong Y, et al. Urinary Iodine Excretion as a Predictor of the Iodine Content of Breast Milk. J Med Assoc Thai. 1999;82(3):284-89.

9. WHO. Progress toward the Elimination of Iodine Deficiency Disorders (IDDs). Geneva: WHO; 1999. p.1-33.

10. Seibold-Weiger K, Wollmann H, Rendi J, Ranke M, Sper C. Iodine Concentration in the Breast Milk of Mothers of Premature Infants. Z Geburtshilfe Neonatol. 2003;203(2):81-85.

11. Granner DK. Thyroid Hormones. In: Murray RK, Granner DK, Mayes PA, Rodwell VW, editors. Harper's Biochemistry. 25th ed. London: Hall International (UK) Limited; 2000. p.561-66.

12. Nelson M, Phillips DI, Morris JA, Wood T. Urinary Iodine Excretion Correlates with Milk Iodine Content in Seven British Town. J Epidemiol Community health. 1998;42(1):72-75. 